\title{
Management of pelvic fracture-associated urethral injuries: A survey of Canadian urologists
}

\author{
Nathan Colin Wong, MD;1 Christopher B. Allard, MD; Shawn Dason, MD; ${ }^{1}$ Patricia Farrugia, MD;2 \\ Mohit Bhandari, MD,2 Timothy O. Davies, $M D^{1}$
}

'Division of Urology; '2Division of Orthopedic Surgery; McMaster University, Hamilton, ON, Canada

Cite as: Can Urol Assoc J 2017;11 (3-4):74-8. http://dx.doi.org/10.5489/cuaj.4154

Published online March 16, 2017

\section{Abstract}

Introduction: The management of pelvic fracture-associated urethral injuries (PFUI) is not standardized and optimal management is controversial. We surveyed Canadian urologists about their experiences and opinions regarding optimal management of PFUI.

Methods: Canadian urologists were surveyed via an anonymous, bilingual, web-based, 12-item questionnaire. A total of 735 Canadian urologists were invited to participate via email distributed by the Canadian Urological Association.

Results: Of the 146 urologists who participated (19.9\% response rate), the majority practice at a trauma centre (53.2\%), but manage only 1-5 PFUI/year (71.5\%). Most participants (82.6\%) favour primary realignment compared to suprapubic (SP) tube with delayed repair $(15.3 \%)$ and immediate reconstruction (2.1\%). Compared to SP diversion and delayed repair, the majority of participants believe primary realignment is associated with equivocal incontinence $(61.2 \%)$ and erectile dysfunction rates $(75.8 \%)$, but has lower stricture rates $(73.0 \%)$. Among respondents who perform primary realignment, $45.4 \%$ concurrently place a SP tube, while $54.6 \%$ do not. While $91 \%$ believe SP tubes do not increase the risk of pelvic hardware infections, $31.6 \%$ report that orthopedic surgeons alter their management of pelvic fractures in the presence of a SP tube. Conclusions: Most Canadian urologist respondents - even those practicing at trauma centres - manage very few PFUIs/year. There is reasonable consensus among respondents that primary realignment is favourable to delayed or immediate reconstruction, but discordance on whether or not to place concurrent SP tubes. The urological and orthopedic consequences of SP tubes in the management of traumatic urological injuries warrant further investigation.

\section{Introduction}

Pelvic fracture urethral injuries (PFUI) occur in about 3-25\% of patients with disruption of the pelvic ring. ${ }^{1,2}$ They typically result from shearing forces to the bulbomenbranous junction that leads to avulsion of the urethra from its fixed position at the urogenital diaphragm. Management typically demands a multidisciplinary approach, with involvement of the trauma team, orthopedic surgeon, and urologist, each of whom has a direct impact on patient morbidity and mortality. ${ }^{3-5}$ In the acute setting, resuscitation requires aggressive fluid hydration and close monitoring of volume status. Due to their injuries, these patients are often unable to urinate and urologists are required to obtain immediate urinary drainage.

Optimal management is controversial and most data arise predominately from retrospective series. ${ }^{6-11}$ Multiple treatment options are available, including gentle single attempt to pass a well-lubricated urethral catheter, suprapubic (SP) diversion (either percutaneous or open) with subsequent delayed urethroplasty of the inevitable stricture, primary endoscopic realignment over a urethral catheter with or without concurrent SP diversion, or immediate surgical exploration with primary reconstruction. ${ }^{6}$

Although treatment requires close coordination with the orthopedic surgeons, the impact of the management of urethral injuries on the surgical repair of the concomitant orthopedic injuries is also not widely acknowledged in the urological literature. Orthopedic surgeons may have concerns about internal hardware infection used in pelvic fixation due to urine extravasation into the retropubic space from SP tubes. ${ }^{6}$ Thus, the presence of SP tubes placed by the urologist may change the orthopedic surgeon's decisionmaking on whether to place internal hardware, subsequently affecting patient morbidity and mortality. ${ }^{6}$

Presently, there is no consensus regarding optimal management of these complex trauma patients and it is unclear whether urologists and orthopedic surgeons are aware of how one's treatment may affect the other. Herein, we assessed the experiences and opinions of Canadian urologists on the management of PFUI via a web-based survey. 


\section{Methods}

Canadian urologists were surveyed via an anonymous, bilingual (English and French), web-based, 12-item multiple-choice questionnaire after approval by the Research Ethics Board. The link to the online questionnaire was distributed via electronic mail to urologists associated with the Canadian Urological Association (CUA). Face validity of the survey was optimized through input from multiple urologists and orthopedic surgeons, including attendings and residents at trauma and non-trauma centres.

The questionnaire was developed in keeping with previously published recommendations on survey design. ${ }^{12}$ It was divided into four main topics: 1 ) demographic information; 2) optimal management of a hemodynamically stable patient with PFUI; 3) opinion on the effect of SP tubes on hardware infection and orthopedic surgeon decision-making; and 4) opinion on the relative complication rates, in particular urethral strictures, incontinence, and erectile dysfunction (ED), of primary realignment compared to initial SP drainage followed by delayed urethroplasty. Results were collected and analyzed using Survey Monkey ${ }^{\circledR} 2014$ and SPSS IBM Statistic Desktop version 22.0.

\section{Results}

The survey was distributed to 735 urologists with an overall participation rate of $19.9 \%$ (146/735). Demographic information is shown in Table 1. Most respondents are employed in Ontario $(52.1 \%)$, followed by British Columbia (13.7\%), then Quebec $(8.2 \%)$ and Alberta (8.2\%). Many of the responders have either practiced urology for $1-5$ years $(23.3 \%)$ or $>20$ years $(23.3 \%)$. About $21.9 \%$ and $4.1 \%$ identified themselves as urology residents and fellows, respectively. Participants commonly work at either community hospitals $(31.5 \%)$ or trauma centres $(53.2 \%)$ : level $1(29.4 \%)$, level $2(1.4 \%)$, or level $3(22.4 \%)$. The number of PFUI cases managed per year by participants was quite low - approximately $71.5 \%$ of respondents manage only $1-5$ PFUI(s)/year, while $19.4 \%$ do not see any cases in their practice. Only $2.1 \%$ (3/144) of the participants manage $>10$ PFUls/year and all of these urologists work at trauma hospitals.

With regards to the initial management of a stable patient who presents with a PFUI, most participants (82.6\%) favour primary realignment, while $15.3 \%$ and $2.1 \%$ favour initial SP diversion with delayed urethroplasty and immediate primary reconstruction, respectively (Fig. 1). Among the urologists who would perform primary realignment (119/144), 45.4\% (54/119) would concurrently place a SP tube, while $54.6 \%$ (65/119) would not. Subgroup analysis of those participants who manage $>10$ PFUIs/year shows that all prefer primary realignment $(100 \%)$.

As shown in Fig. 2, compared to initial SP diversion and delayed repair, the majority of participants believe primary

\begin{tabular}{|c|c|c|c|}
\hline Survey questions & & Number & Percent \\
\hline Total number of part & cipants & 146 & 100 \\
\hline \multirow{5}{*}{$\begin{array}{l}\text { Where do you } \\
\text { practice? }\end{array}$} & British Columbia & 20 & 13.7 \\
\hline & Prairies & 25 & 17.1 \\
\hline & Ontario & 76 & 52.1 \\
\hline & Quebec & 12 & 8.2 \\
\hline & Atlantic & 13 & 8.9 \\
\hline \multirow{6}{*}{$\begin{array}{l}\text { How many years } \\
\text { have you been } \\
\text { practicing? }\end{array}$} & $1-5$ & 34 & 23.3 \\
\hline & $6-10$ & 18 & 12.3 \\
\hline & $11-20$ & 22 & 15.1 \\
\hline & $>20$ & 34 & 23.3 \\
\hline & Resident & 32 & 21.9 \\
\hline & Fellow & 6 & 4.1 \\
\hline \multirow{5}{*}{$\begin{array}{l}\text { How many pelvic } \\
\text { fracture-associated } \\
\text { urethral injuries do } \\
\text { you manage per } \\
\text { year? }\end{array}$} & 0 & 28 & 19.4 \\
\hline & $1-5$ & 103 & 71.5 \\
\hline & $6-10$ & 10 & 6.9 \\
\hline & $11-15$ & 3 & 2.1 \\
\hline & $>15$ & 0 & 0.0 \\
\hline \multirow{5}{*}{$\begin{array}{l}\text { What type of } \\
\text { hospital do you } \\
\text { practice at? }\end{array}$} & Community & 45 & 31.5 \\
\hline & Academic, non-trauma & 22 & 15.4 \\
\hline & Level 1 trauma centre & 42 & 19.4 \\
\hline & Level 2 trauma centre & 2 & 1.4 \\
\hline & Level 3 trauma centre & 32 & 22.4 \\
\hline
\end{tabular}

realignment has lower stricture rates $(71.7 \%$ compared to $20.7 \%$ equivocal and $7.6 \%$ higher stricture rates). Subgroup analysis of those who would initially place a SP tube and perform delayed repair, only $27.3 \%$ believe primary realignment has lower stricture rates and $45.5 \%$ feel primary realignment has equivocal stricture rates compared to delayed repair. Most participants also believe that compared to delayed reconstruction, primary realignment is associated with equivocal incontinence rates $(61.2 \%)$ and equivocal ED rates $(74.7 \%)$.

Although 91\% do not believe the presence of SP tubes actually increases the risk of infections of pelvic hardware, $31.6 \%$ of participants report that orthopedic surgeons alter their management of pelvic fractures in the presence of a SP tube and would less likely place fixation hardware if a SP catheter is present. Compared to those who would perform primary realignment with concurrent SP tube placement, those who would perform primary realignment without SP tubes feel that the presence of SP tubes would make orthopedic surgeons less likely to place fixation hardware $(38.3 \%$ compared to $15.1 \%$ with SP tubes; $\mathrm{p}<0.05$ ).

\section{Discussion}

The optimal method and timing of surgical repair of a patient presenting with a PFUI involves a multidisciplinary approach, but remains controversial. In our study of 146 Canadian urologists, the most popular management strategy 


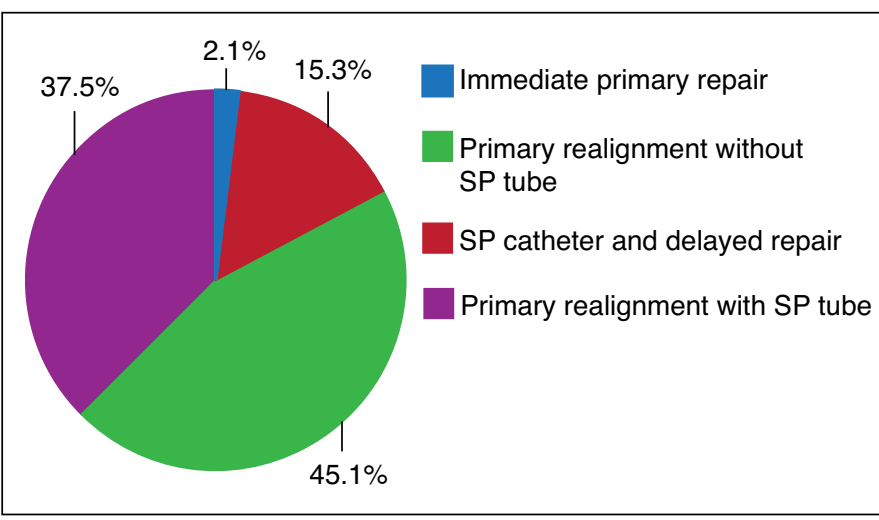

Fig.1. Survey response for the optimal urological management of a hemodynamically stable patient with pelvic fracture-associated urethral injury. SP: suprapubic.

of a hemodynamically stable patient with a PFUI was primary realignment, followed by SP diversion with delayed repair, and then immediate reconstruction. Of those who favour primary realignment, about $50 \%$ would concurrently place a SP tube, while the other half would not. Unfortunately, there is no good evidence to support one practice over the other. Anecdotally, some respondents report that SP tubes act as a safety access, while others feel it is not necessary and its presence affects orthopedic decision-making as to whether or not to place internal hardware for the management of the pelvic fracture.

Some urologists, however, advocate for immediate SP diversion with delayed elective urethroplasty. ${ }^{8,9}$ Initial SP diversion may assist in immediate urinary drainage, prevention of urinary clot retention, prevention of urinary extravasation from the disrupted urethra, and facilitation of cutto-the-light endoscopic urethrotomy. ${ }^{4}$ In cases of PFUI, the initial reconstruction offers the best chance of a successful outcome, as further repairs become more technically challenging due to the inevitable presence of scar formation. Surgeons may opt for initial SP drainage followed by delayed reconstruction after allowing for urethral tissue healing, for reabsorption of the pelvic hematoma, and for the patient to recover from other injuries. The initial surgeon may also refer the patient to specialized urologist with more expertise in the perineal anatomy for delayed reconstruction.

Urologists must nonetheless be mindful of how their involvement impacts the management of the associated orthopedic injuries. Orthopedic surgeons may be hesitant to perform internal fixation after a SP catheter has been placed due to concern regarding contamination by urinary extravasation and the presence of a tract that could facilitate subsequent infections. ${ }^{13}$ Although open reduction and internal fixation is recommended for most of these injuries, some othropedic literature suggest external fixation of pelvic fractures in the face of urethral injuries due to the possible increased risk of secondary infection from SP tubes. ${ }^{5,13}$

There is no scientific evidence to indicate that SP tubes actually increase orthopedic hardware infections and concerns regarding the use of SP diversion in patients undergoing internal fixation vary based on individual surgeon and institutional practice patterns. ${ }^{9,13}$ In our study, although 91\% believe SP tubes do not increase the risk of pelvic hardware infections, $31.6 \%$ of urologists report that orthopedic surgeons alter their management of pelvic fractures in the presence of SP tubes.

As orthopedic surgeons may believe SP tubes increase the risk of infections, it may affect how and when they chooses to manage the pelvic fractures. ${ }^{4,5}$ A retrospective series of 23 patients with PFUI by Mayher et al showed that orthopedic

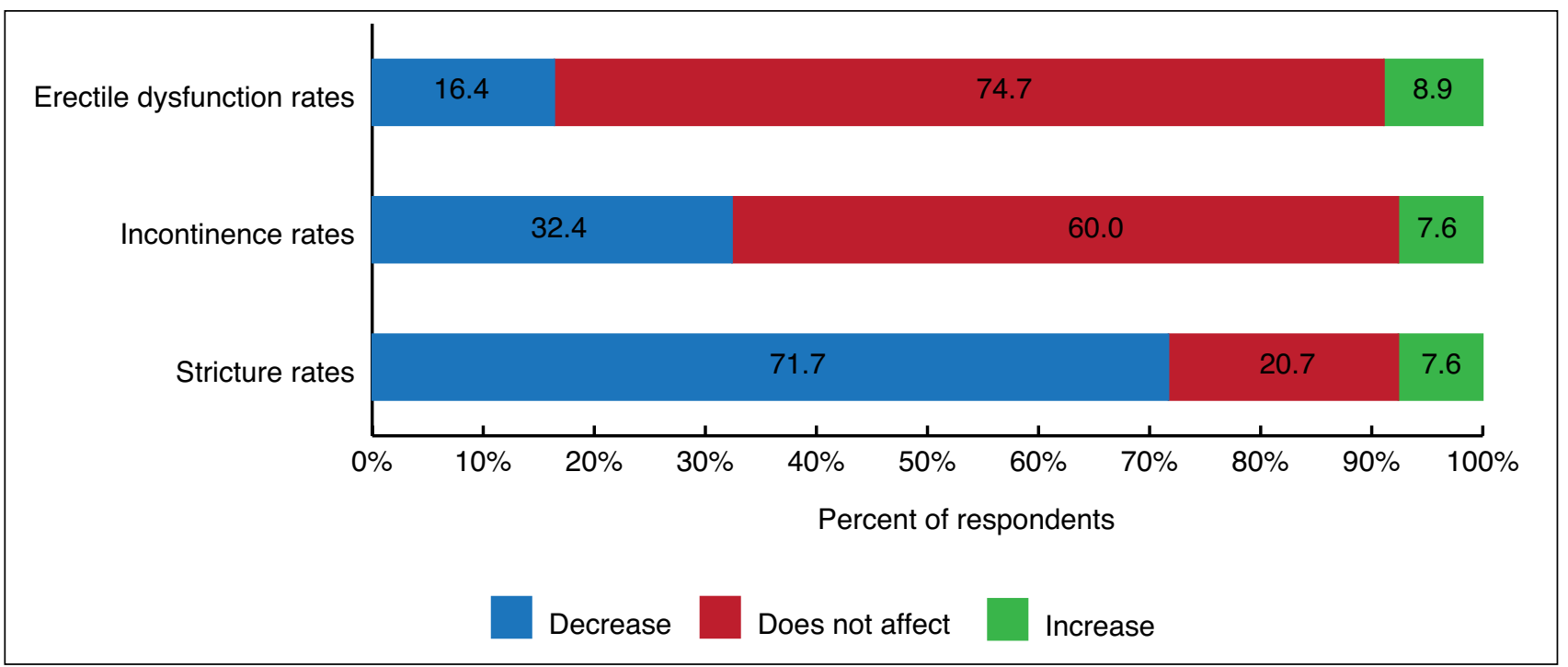

Fig. 2. Comparison of the respondents' perception of complication rates between primary realignment and suprapubic diversion with delayed repair. 
surgeons altered their surgical management in $35 \%$ of cases due to concern over SP catheters, and patient morbidity was increased as a direct result. ${ }^{5}$ In their series, SP catheters precluded orthopedic fracture repair in four patients who were subsequently treated conservatively with prolonged immobilization. These patients required long-term physiotherapy and $75 \%$ became unable to resume their previous employment secondary to chronic pelvic pain. Alternatively, no patients managed with primary realignment in their series faced similar adverse outcomes.

Thus, endoscopic primary realignment has been increasing in popularity, especially with the availability of flexible cystoscopy. ${ }^{7,14}$ However, success rates reported in primary realignment series are not well-defined and vary considerably, ranging from $11-86 \% .^{8,9,14}$ Although the benefits remain debatable, those who advocate for primary realignment stress the importance of reestablishing urethral continuity to obviate the need for or difficulty of future urethoplasties. The strictures that do develop may be shorter in length and with the urethra aligned, the surgeon may successfully treat these patients endoscopically.

In a recent systematic review and meta-analysis of nine articles comparing primary realignment and initial SP cystotomy for the management of PFUI, primary realignment appears to reduce the incidence of stricture formation. ${ }^{10}$ Compared to delayed repair, primary realignment was shown to reduce stricture rates by $37.2 \%$, with a number needed to treat of $2.76 .^{10}$ The meta-analysis showed no significant differences with regard to the development of incontinence or ED between primary realignment and initial SP diversion. However, contemporary thinking is that the severity of PFUI and concurrent injuries are actually responsible for the associated complications rather than the timing or type of surgical intervention.

Some authors, however, advocate against primary realignment. Tausch and Morey reported that at their centre, where delayed urethropasty after SP diversion is the preferred management algorithm, urethropasty successfully manages the stricture in $100 \%$ of patients initially managed by SP diversion compared to only $82 \%$ in those managed by initial primary realignment. ${ }^{8,9}$ The mean time to definitive resolution of the stricture was shorter in those treated with SP tube with delayed repair compared to primary realignment (six months vs. 25 months; $\mathrm{p}<0.01){ }^{8}$ The authors showed that primary realignment did not facilitate ease of urethroplasty when needed, as there was no significant difference in operative time or stricture length. Further, the majority of those treated with primary realignment required multiple endoscopic urethral interventions (median four intervention vs. none; $p<0.01$ ) and experienced more adverse events compared to initial SP diversion $(82 \%$ vs. $9 \% ; \mathrm{p}<0.05)$. Although potentially avoiding urethroplasty, primary realignment may further subject the patient to painful self-dilatations, multiple office procedures, lost time from work and income, and a significant delay in return to unobstructed voiding. ${ }^{8}$ These procedures can cause bleeding and pain, as well as further injure the urethra, causing false passages and scar formation and making future urethroplasty a more challenging operation. ${ }^{8}$

This survey does have recognized limitations, such as the relatively low participation rate and that most respondents were from a single province, Ontario. It would have been interesting to evaluate whether participants' location of geographic training affected practice, but our participation rate was unfortunately too low to determine this. Furthermore, most respondents only manage 1-5 or no PFUIs(s) per year, which is likely due to the fact that PFUIs are an uncommon occurrence and patients are typically transferred to a trauma institute for multidisciplinary management.

\section{Conclusion}

This survey draws upon practices of Canadian urologist in the current management of PFUI. Although there is reasonable consensus among respondents that primary realignment is favourable to delayed or immediate repair, there is noteworthy discordance as to whether or not SP tubes should be used as an adjunct to primary realignment. The urological and orthopedic consequences of SP tubes in the management of traumatic urological injuries warrant further investigation. This study looks to increase opportunities for education, communication, and collaboration between urologists and orthopedic surgeons, and can serve as a foundation for further research into the optimal management of PFUI.

Competing interests: Dr. Davies has been an advisor for Allergan, Boston Scientific, and Pfizer; and has received honoraria from Allergan, Astellas, Boston Scientific, and Pfizer. The remaining authors report no competing personal or financial interests.

This paper has been peer-reviewed.

\section{References}

1. Coffield KS, Weems WL. Experience with management of posterior urethral injury associated with pelvic fracture. J Urol 1977; 117:722-4.

2. Pokorny M, Pontes JE, Pierce JM Jr. Urological injuries associated with pelvic trauma. J Urol 1979;121:4557.

3. Routt ML Jt, Simonian PT, Ballmer F. A rational approach to pelvic trauma. Resuscitation and early definitive stabilization. Clin Orthop Relat Res 1995;318:61-74.

4. Lee J, Abrahamson BS, Harrington $T G$, et al. Urological complications of diastasis of the public symphysis: A trauma case report and review of world literature. J Trauma 2000;48:133-6. https://doi.org/10.1097/00005373-200001000-00024

5. Mayher BE, Guyton JL, Gingrich JR. Impact of urethral injury management on the treatment and outcome of concurrent pelvic fractures. Urology 2001;57:439-42. https://doi.org/10.1016/500904295(00)01038-4

6. Morey AF, Brandes S, Dugi DD 3rd, et al for the American Urological Association. Urotrauma: AUA guideline. J Urol 2014;192:327-35. htrps://doi.org/10.1016/i.juro.2014.05.004 
Wong et al.

7. Mouraviev VB, Coburn M, Santucci RA. The treatment of posterior urethral disruption associated with pelvic fractures: Comparative experience of early realignment vs. delayed urethroplasty. J Urol 2005; 173:873-6. https://doi.org/10.1097/01.ju.0000152145.33215.36

8. Tausch TJ, Morey AF, Scott JF, et al. Unintended negative consequences of primary endoscopic realignment for men with pelvic fracture urethral injuries. J Urol 2014;192:1720-4. https://doi.org/10.1016/i. juro.2014.06.069

9. Tausch TJ, Morey AF. The case against primary endoscopic realignment of pelvic fracture urethral injuries. Arab J Urol 2015;13:13-6. https://doi.org/10.1016/i.aju.2014.12.005

10. Barrett K, Braga LH, Farrokhyar F, et al. Primary realignment vs suprapubic cystostomy for the management of pelvic fracture-associated urethral injuries: A systematic review and meta-analysis. Urology 2014;83:924-9. https://doi.org/10.1016/j.urology.2013.12.031

11. Webster GD, Mathes GL, Selli C. Prostatomembranous urethral injuries: A review of the literature and a rational approach to their management. J Urol 1983;130:898-902.
12. McColl $E$, Jacoby $A$, Thomas $L$, et al. Design and use of questionnaires: A review of best practice applicable to surveys of health service staff and patients. Health Technol Assess 2001;5:1-256. https://doi.org/10.3310/hta5310

13. Russell TA. Fractures of the hip and pelvis. In: Crenshaw AH, ed. Campbell's Operative Orthopedics. St. Louis, MO: Mosby-Year Book; 1992: 895-897.

14. Gómez RG, Mundy T, Dubey D, et al. SIU/ICUD Consultation on Urethral Strictures: Pelvic fracture urethral injuries. Urology 2014;83:S48-58. https://doi.org/10.1016/i.urology.2013.09.023

Correspondence: Dr. Nathan Colin Wong, Department of Urology, McMaster University, Hamilton, ON, Canada; nathan.wong@medportal.ca 